\title{
Protecting Chemical Plants against Terrorist Attacks: A Review
}

\section{Nima Khakzad and Genserik Reniers*}

Safety and Security Science Group, TU Delft, The Netherlands

\begin{abstract}
Protection of hazardous establishments such as chemical plants intentional incidents has drawn attention from safety and security experts since 9/11 terrorist attacks in the U.S. Although major steps have been taken since, the recent intentional incidents in two chemical plants in France in June and July 2015 revealed the vulnerbaility and attractiveness of chemical plants as potential targets for terrorist groups. Furthermore, the terrorist attcks in Paris in November 2015 have again raised the awareness of potential terrorist acts in chemical plants. The present work is aimed at performing a brief statistical review of current regulations and previous attempts in order to highlight the importance of security improvements in chemical plants with regard to terrorist attacks.
\end{abstract}

Keywords: Terrorist attack; Chemical plants; Physical security

\section{Introduction}

Chemical plants are basically attributed with large inventories of hazardous materials including flammable, explosive, and toxic substances whose accidental or intentional (undesired) release could result in major fires, explosions, or dispersion of toxic gases. Since these hazardous materials are usually stored and handeled under high-pressure high-temperature conditions usually a seemingly inconsequential release can potentially end up as a major incident ${ }^{1}$. The proximity of chemical plants to residential areas and transportation networks especifically in highly industrialized and densly populated European countries and also the emergence of chemical clusters incorporating a number of hazardous establishment and installations within a tight neighborhood even make the consequences of such undesired releases more catastrophic.

As opposed the safety issues in chemical plants which is a matter of random failures, human errors, negligence, or natural hazards, the security issues such as terrorist attacks, sabotage, theft, vandalism, arson, and malicious acts are caused by some human agents - also called adversaries - with an intention of causing maximum damages especially in the case of terrorist attacks. The likelihood of attack is a function of the type of adversaries and possible attack scenarios, and the vulnerability and the attractiveness of the chemical plant under consideration [1]. In the context of intentional events, the vulnerability of a chemical plant is a measure of how susceptiple the plant is to damage under an attack or deliberate act. Likewise, the attractiveness of the plant is a measure of how valuable the plant is in the mind of adversaries. Generaly speaking, the more vulnerable/attractive a chemical plant the higher the likelihood of an attack. Figure 1 illustrates the relationships among the main parts of a security analysis to address the risk of intentional events. As can be seen from Figure 1, both the vulnerability of a chemical plant and the severity of the potential consequences influence the attarctiveness of the plant; the plant vilnerability can also influence (encourage or discourage) the type of threat and the attack scenarios.

\section{Regulations, Facts, and Figures}

Compared to the safety analysis, the importance of security analysis in protecting important infrastructures such as financial institutions, govermental facilities, and aviation industry against intentional events has long been recognized. However, it was mainly after 9/11

${ }^{1}$ In the present study, an incident refers to either an accidental or an intentional event such as fire, explosion, and toxic dispersion.

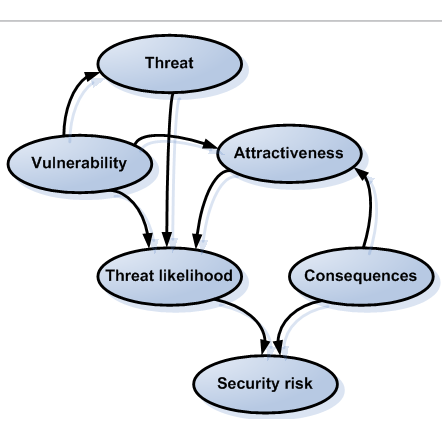

Figure 1: Schematic relation among different parts of a security risk analysis. The arcs imply the causal relationships.

terrorist attacks in the U.S. that the issue of security in other critical infrastructures such as chemical plants begin to draw attention among legislators, authorities, management, and safety and security community. Accordingly, in the U.S. the Centre of Chemical Process Safety (CCPS) prepared a guideline for security and vulnerability analysis of fixed installations in 2002 while in Europe the Organisation for Economic Co-operation and Development (OECD) held a workshop on chemical releases caused by intentional events in Rome in 2003 the report of which was published in 2004. In 2007 the CFATS² (Chemical Facility Anti-Terrorism Standards) came into effect to regulate the security of major hazard chemical plants (called upper tier establishments in Europe according to Seveso legislation) in the US; CFATS was updated more recently, in 2014. In Europe, however, the Council Directive 2008/114/EC provided directives on how to enhance the prevention, preparedness and response to terrorist attacks in European critical infrastructures. However, chemical plants are not considered critical infrastructures in most European countries.

${ }^{2}$ On December 18, 2014, the CFATS was signed into law the Protecting and Securing Chemical Facilities from Terrorist Attacks Act of 2014 (The CFATS Act of 2014).

*Corresponding author: Genserik Reniers, Safety and Security Science Group, TU Delft, The Netherlands, E-mail: genserik.reniers@uantwerpen.be

Received December 10, 2015; Accepted December 14, 2015; Published December 24,2015

Citation: Khakzad N, Reniers G (2015) Protecting Chemical Plants against Terrorist Attacks: A Review. J Socialomics 5: 142. doi:10.4172/2167-0358.1000142

Copyright: @ 2015 Khakzad N, et al.. This is an open-access article distributed under the terms of the Creative Commons Attribution License, which permits unrestricted use, distribution, and reproduction in any medium, provided the original author and source are credited. 
Figure 2 illustrates an ascending trend of the publications in the field of the security amalysis in chemical plants (blue bars in Figure 2) since 9/11 attacks in 2001. As can be noted from Figure 2, compared to the increasing trend of publications in the general domain of chemical plant security analysis the number of publications in the sub-domain of terrorist attacks (red bars in Figure 2) have seen the highest density between 2002 and 2006 and then experienced a more or less decreasing trend since.

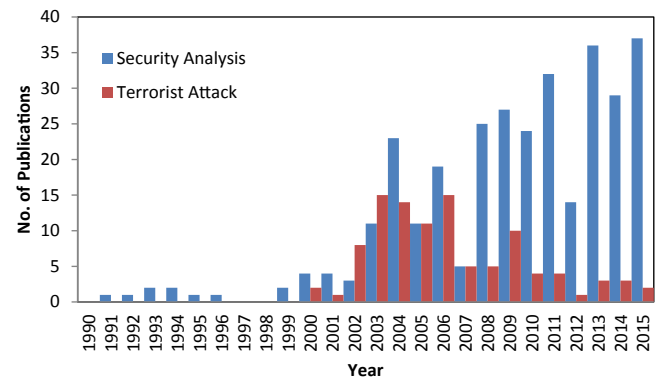

Figure 2: Time distribution of the publications in the domain of security analysis (blue bars) and terrorist attacks (red bars) in chemical plants.

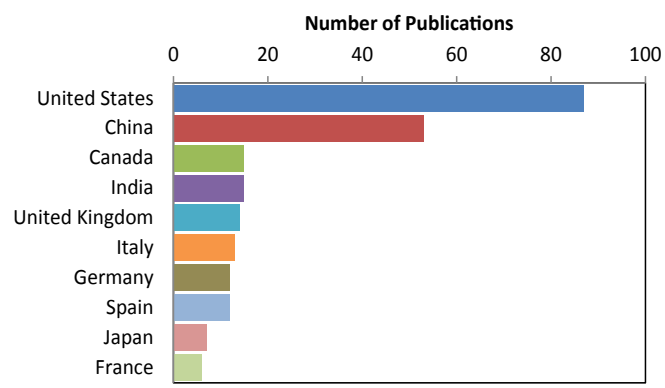

Figure 3: Regional distribution of the publications in the domain of terroris attacks in chemical plants.

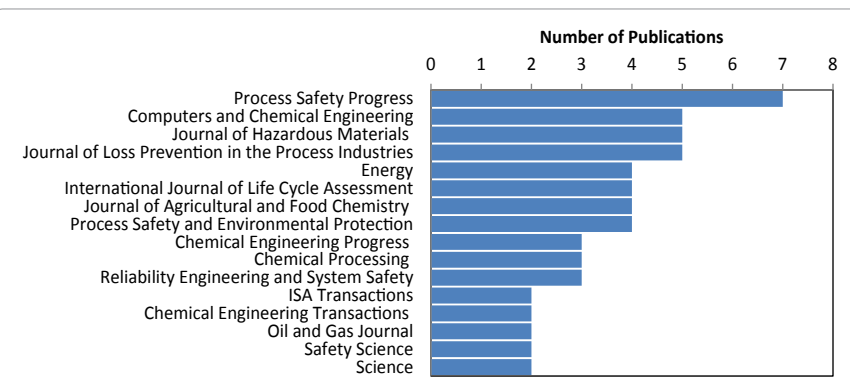

Figure 4: Journal distribution of the publications in the domain of terrorist attacks in chemical plants.

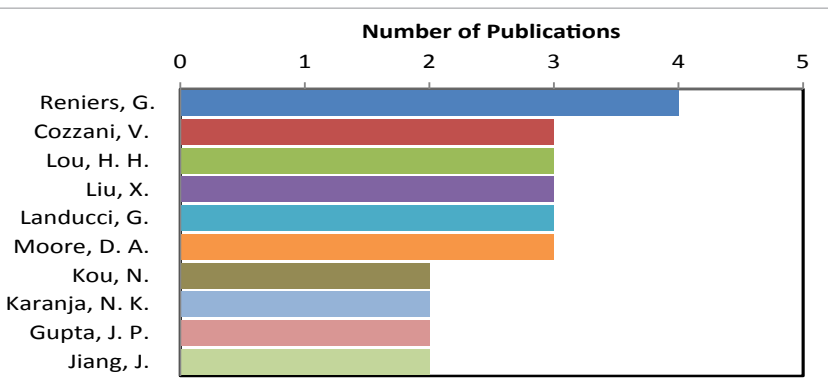

Figure 5: Authorial distribution of the publications in the domain of terrorist attacks in chemical plants.
The high concentration of publications in terrorist attack in the foregoing time interval can well be explained as a result of the 9/11 terrorist attcks' aftermath which started in 2002 and boosted by the train bombings in Madrid in 2004 and the suicide bombings on the underground and bus transportation lines in London in 2005 (www. ndtv.com). Aside from the high density of publications within a short aftermath of terrorist attacks which can be deemed quite a natural response to the event, the reasons for the relatively lower number of publications in terrorist attacks are manifold. According to a survey conducted by Reniers [2] in Belgium, in chemical companies the likelihood of extreme security issues such as those of successful terrorist attacks is considered very low though the high consequences of such attacks can readily compensate the low probability thereof. Instead, the focus has been on high-probability low-consequence security issues such as theft or sabotage by disgruntled employees or contractors. Another reason probably lies in the fact that although most of work in the field of terrorist security analysis has been eventdriven (e.g. 9/11 attacks), an urge for security analysis in chemical plants and developing methodologies and countermeasures has been driven to a large extent by legislation (e.g., by CFATS). In this regard, the relatively lower amount of research and thus publications in the field of chemical plants' terrorist security analysis stems from a lack of binding legislations especially in chemical industry [3]. Figure 3 depicts the regional distribution of relevant publications.

As pinpointed by Reniers [2], in the chemical industry the issues of safety and security are mainly considered as parts of the same policy and being implemented and managed under similar guidelines and procedures. This attitude toward security largely originates from the perspective that if safety is well managed the security will also be well maintained within the chemical plant premises due to extensive common grounds between the two. This inclination to the security, however, overlooks the fact that although safety and security risk assessments have common parts (e.g., consequence analysis) they differ in hazard analysis. Against to safety assessment in which the hazard analysis is focused on the identification of random failures and the estimation of their probabilities, in security assessment the hazard analysis - better known as threat analysis - comprises the analysis of the type of adversaries and attack scenarios along with the vulnerability and the attractiveness assessment of the chemical plant of interest. As such, the security analysis not as a sub-domain of safety analysis but as an equally important domain should be taken into consideration in chemical plants.

Figure 4 displays the journals containing the publications on the issue of terrorist security analysis in chemical plants. As can be noted, a vast majority of the publications has been appeared in journals with the safety as the main theme, indicating the dominant mindset toward security as a sub-domain of safety. Nevertheless, it should be noted that the lack of journals in the field of physical security has also contributed to the publication of security related papers in safety-oriented journals.

Figure 5 show the authors with the highest number of publications in the domain of terrorist security analysis in chemical plants whereas Figure 6 depicts the distribution of the publications according to the subject area with the highest concentration in Engineering, Environmental Science, Chemical Engineering, and Agricultural and Food, in a descending order.

\section{Conclusions and Recommendations}

The question arised here is whether chemical plants are on the top list of terrorist attacks when we face the emergence of brutal terrorist 


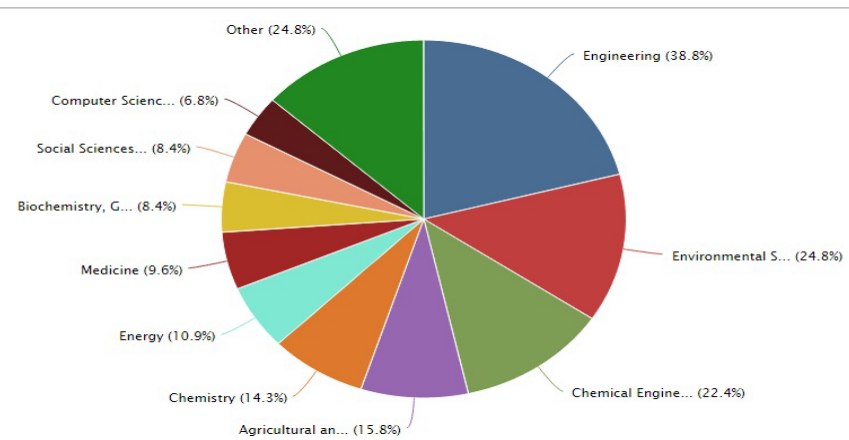

Figure 6: Subject areal distribution of the publications in the domain of terrorist attacks in chemical plants.

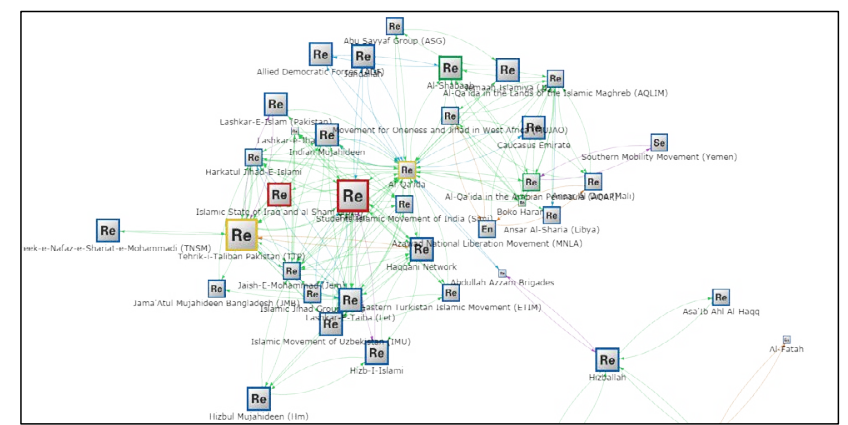

Figure 7: Terrorist groups and the relationships among them (BAAD Global Network).

groups which not only are well-equipped and well-organized but also willingly sacrifice their own lives to massacre people in cafes, restaurants, and theatres, like what happened on November 13, 2015 in Paris. Would they bother themselves to attack chemical plants when they are able to take lives of many people without any need for complicated terrorist infrastructures and just by means of suicide bombers or car bombs in crowded areas, spreading the feelings of terror and panic throughout the society? The short answer is yes. Chemical plants have all the potential needed by terrorists not only to make massive manslaughter but also to damage the economy and functionality of goverments [4]. Safety issues (accidental events) in chemical plants over the past decades such as the leakage of MIC (methyl isocyanate) in Bohpal, India in 1984 which caused around 10,000 casualties or the explosion of an ammonia plant in Texas, U.S. in 2013 which left more than 200 casualties and huge destruction in the local community all indicate the capability of chemical plants in fostering the objectives of terrorists.

Most recently, the intentional events in two chemical plants in France in June 2015 (BBC News) and July 2015 (BBc News) have exposed the vulnerability and attractiveness of chemical plants as potential targets for such delibrate acts. The former attack resulted in one fatality while the latter attack did not leave any fatalities but economic damages. Despite their relatively minor consequences, these attacks raised the chemical industry's awareness of imminent terrorist attacks and the need for taking effective measuress not only to reduce the attractiveness of chemical facilities but to reduce the potential consequences of such successful attacks [5].

As pinpointed by Lippin [3,6] an major strategy to reduce both the attractiveness and the severity of consequences of chemical plants in case of terrorist attcks would be the implementation of inherently safer technologies (ISTs). IST $[7,8]$ is not a tool or technology but rather a philosophy and way of thinking to achieve built-in safety within a chemical facility rather than by means of add-on safety measures. IST includes five principles, which are (i) minimizing the amount of hazardous materials present at any one time in the chemical facility, (ii) substituting hazardous materials or processes with less hazardous materials or processes, (iii) moderating the strength of a process by, for example, reducing the temperature or pressure, (iv) simplifying the design and process by reducing unnecessary complexities in order to reduce errors, and (v) limiting the effect of an event by appropriate design and location of major hazard installations. The role of IST is twofold since through which not only the risk of intentional events but also the risk of accidental events can significantly be reduced.

Similar to IST, land use planning (LUP) is a non-structural safety measure to protect public from the consequences of major accidents in major hazard installations [9] with an ample application to reduce the attractiveness and consequences of terrorist attcks. In LUP, the land around a major hazard installation such as a chemical plant is divided into zones wherein according to the level of risk and the vulnerability of the population at risk each zone is designated to specific developments (e.g., residential houses, schools, hospitals, etc) with limited number of people. As such, in case of an incident, whether accidental or intentional, a lower number of people with lower levels of vulnerability would be exposed to dangerous doses (e.g., heat radiation, overpressure, toxic gases) which in turn help reduce either the extent or the severity of casualties. Bearing in mind that terrorist groups usually seek opportunities to inflict maximum damages, learning that an intentional incident in a chemical plant would not give rise to high casualties is likely to decrease the attractiveness of the plant and thus discourage a potential attack (see the relation between consequences and attractiveness in Figure 1.

Figure 7 demonstrates a number of terrorist groups around the world with a variety of ideologies including Religious (Re), Separatist (Se), and Ethnic (En) adversaries (BAAD Global Network). The figure also depicts the complicated relationships among these groups. It seems too optimistic to think we could eliminate these terrorist groups or even stop them from carrying out terrorist attcks. But what we can do is stop them from turning our own infrastructure against us to cause mass casualties [10-17].

\section{References}

1. Bajpai S, Gupta JP (2005) Site security for chemical process industries. Journal of Loss Prevention in the Process Industries 18: 301-309.

2. Reniers $G$ (2012) Security within chemical process industry: survey results from Flanders, Chemical Engineering Transactions, Belgium 26: 465-470.

3. www.start.umd.edu/news/are-us-chemical-facilities-still-open-terrorist-attacks.

4. Jochum C (2005) Can chemical plants be protected against terrorist attacks? Process Safety and Environmental Protection 83: 459-462.

5. www.rsc.org/chemistryworld/2015/07/failed-terrorist-attack-chemical-plantsecurity.

6. Lippin TM, McQuiston TH, Bradley-bull K, Burns-Johnson T, Cook L, Gill ML, Howard D, Seymour TA, Stephens D, Williams BK, et al. (2006) Chemical plants remain vulnerable to terrorists: A call to action. Environmental Health Perspectives 114: 1307-1311.

7. Keltz T (1996) Inherently safer design: the growth of an idea. Process Safety Progress 15: 5-8.

8. Khan F, Amyotte $P$ (2003) How to make inherent safety practice a reality. Canadian Journal of Chemical Engineering 81: 2-16.

9. Khakzad N, Reniers G (2015) Risk-based design of process plants with regard to domino effects and land use planning. Journal of Hazardous Materials 299: 289-297.

10. CCPS Centre for Chemical Process Safety (2003) Guidelines for Analyzing 
and Managing the Security Vulnerabilities of Fixed Chemical Sites. American Institute of Chemical Engineers, New York, Wiley; ISBN-13: 978-0816908776.

11. OECD (2004) Organisation for Economic Co-operation and Development (2004) Report of the Workshop on Communication related to Chemical Releases Caused by Deliberate Acts, Paris.

12. www.dhs.gov/chemical-facility-anti-terrorism-standards.

13. Council Directive (2008) 114/EC on the identification and designation of European critical infrastructures and the assessment of the need to improve their protection. Official Journal of the European Union 345: 75-82.

14. www.ndtv.com/world-news/the-seven-deadliest-attacks-in-europe-indecades-1243261.

15. www.bbc.com/news/world-europe-33284937.

16. www.bbc.com/news/world-europe-33537345.

17. www.start.umd.edu/baad/network/2012. 